\title{
RFID Tag for Toll-Collection Systems
}

\author{
Sergio Buenrostro Rocha ${ }^{1}$, Roberto Herrera Charles ${ }^{1}$, José Luis Medina Monroy ${ }^{2}$, \\ Andrés Calvillo Téllez ${ }^{1}$ \\ ${ }^{1}$ Instituto Politécnico Nacional, Centro de Investigación y Desarrollo de Tecnología Digital, \\ Tijuana, Baja California, Mexico \\ sbuenrostro@citedi.mx, robcharles@citedi.mx, calvillo@citedi.mx \\ ${ }^{2}$ Centro de Investigación Científica y de Educación Superior de Ensenada, Ensenada, B.C., \\ Mexico \\ jmedina@cicese.mx
}

\begin{abstract}
The installation of an RFID tag on a vehicle's windshield for Automatic Vehicle Identification AVI applications has become a challenge for RFID users and service providers, since in some situations the tag is not read properly because some customers do not follow instructions of the recommended locations for installation. This problem is because each location of the windshield provides different distances to the car hood, car roof and A-pillars, and these metallic surfaces directly interact with the radiation resistance of the tag antenna and consequently change its performance (tag read range, frequency, radiation pattern, etc). There are locations in the windshield where the read range of the tag is severely reduced and in others it is greatly benefited. In the present work, an RFID tag for vehicle windshield with the Higgs 3 chip is developed. The tag is designed to operate at the $865 \mathrm{MHz}-868 \mathrm{MHz}$ frequency band and it can be used in Europe, Asia and South Africa. It was observed that its read range is longer at any point of the windshield than that provided by the commercial RFID tag SMARTRAC DogBone with Monza 4 chip that has been well accepted internationally. In order to design the tag, the modeling of the antenna was performed by electromagnetic analysis using the method of moments, then it was prototyped and characterized directly in vehicles. It was also performed an analysis of the different locations of the windshield in order to find the best and worst locations to install the tag.
\end{abstract}

Keywords: RFID, tag, toll.

\section{$1 \quad$ Introduction}

In recent years, Radiofrequency Identification (RFID) systems have attracted much attention, particularly in the ultra-high frequency (UHF) band [1]. Radio Frequency Identification (RFID) is a wireless technology used for the identification and collection of data of objects, people or animals in digital form and automatically or manually. RFID is an alternative to bar code, but with superior capabilities since the readings are made using electromagnetic waves. A basic RFID system consists of a base station called reader or interrogator and a set of remote transponders called RFID tags. A basic interrogator consists of a reader antenna, a coaxial cable, RFID reader, network cable and a computer with dedicated software to manage the readings of the tags $[2,4,8$, and 
9]. A basic RFID system is shown in Figure 1, where it is also possible to observe how an RFID tag is attached to an object to be identified.



Fig. 1. Basic RFID System.

A typical RFID tag consists of an antenna and an application specific integrated circuit chip (ASIC) which contains an internal read/write memory and can have dimensions of at least $0.25 \mathrm{~mm}^{2}$. The tag antenna may be printed on a dielectric substrate that may be flexible or non-flexible, planar or non-planar. The size of an RFID tag can measure some few centimeters, and most of the times it is desired to be as small as possible. RFID tags can be passive (they do not require battery and are completely powered by the power emitted by the reader), semi-passive and active (require battery) $[2,8,9$, and 10]. As an example, it is shown in figure 2 the composition of a basic RFID tag. The size of this tag is approximately $98 \mathrm{~mm} \times 12 \mathrm{~mm}$.

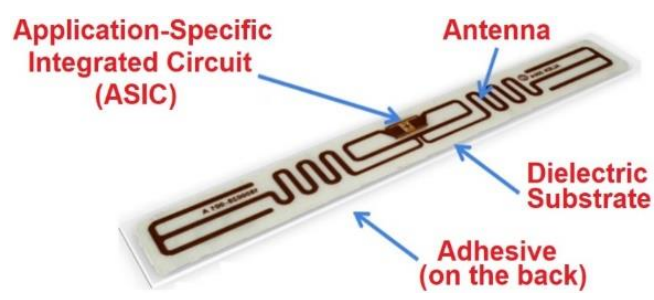

Fig. 2. Composition of an RFID tag.

The number of applications for RFID systems has grown rapidly in industries such as the Internet of Things, access control, inventory control, distribution logistics, security systems, manufacturing process control, medical and biological applications, patient identification, localization and monitoring in hospitals, supermarkets, shops, baggage screening at airports, livestock, human, vehicular application, railway, etc. [1, 18].

Much effort is now being devoted to the development of various UHF applications and solutions. Standardization organizations are working with governments to harmonize UHF frequencies. However, the operating frequency range varies from region to region. UHF bands are currently divided into four globally used regions: China (840-845 MHz), Europe and Asia (865-868 MHz), America (902-928 MHz), Japan (950-956 MHz) [3, 8, 17, 18, and 19]. 
The most important RFID system performance feature is the read range of the tags, and this is the maximum distance of the RFID reader in which it still can read or write information on the tag. The read range of the tag is defined with respect to a certain speed or successful reading/writing percentage which tends to decrease until it becomes zero as the tag moves away from the reader antenna. Generally, it is preferred that the antenna of the tag has the property of omni-directional radiation to ensure identification from all directions [9].

A good impedance matching between the antenna and the chip must be achieved to assure a maximum power transfer between the antenna and the tag chip. The AVI System that uses RFID emerges as a faster and more effective solution to the manual method of toll collection, where problems of vehicle congestion and delay can be experienced. Automatic collection is done through a pre-paid account assigned to the RFID tag belonging to the owner of the vehicle. This makes the toll transaction more convenient for public use [20].

Figure 3 shows how it works an electronic toll collection (ETC) [21]: When the vehicle approaches the tolling booth, the motion sensors detect the vehicle, then it is initialized the RFID reading system. Once the tag is detected and the vehicle is automatically classified by other sensors, the toll collection is executed and then the traffic barrier is lifted, so that traffic circulates in this way. If there was no tag detected the cameras will take pictures of the license plate for processing.

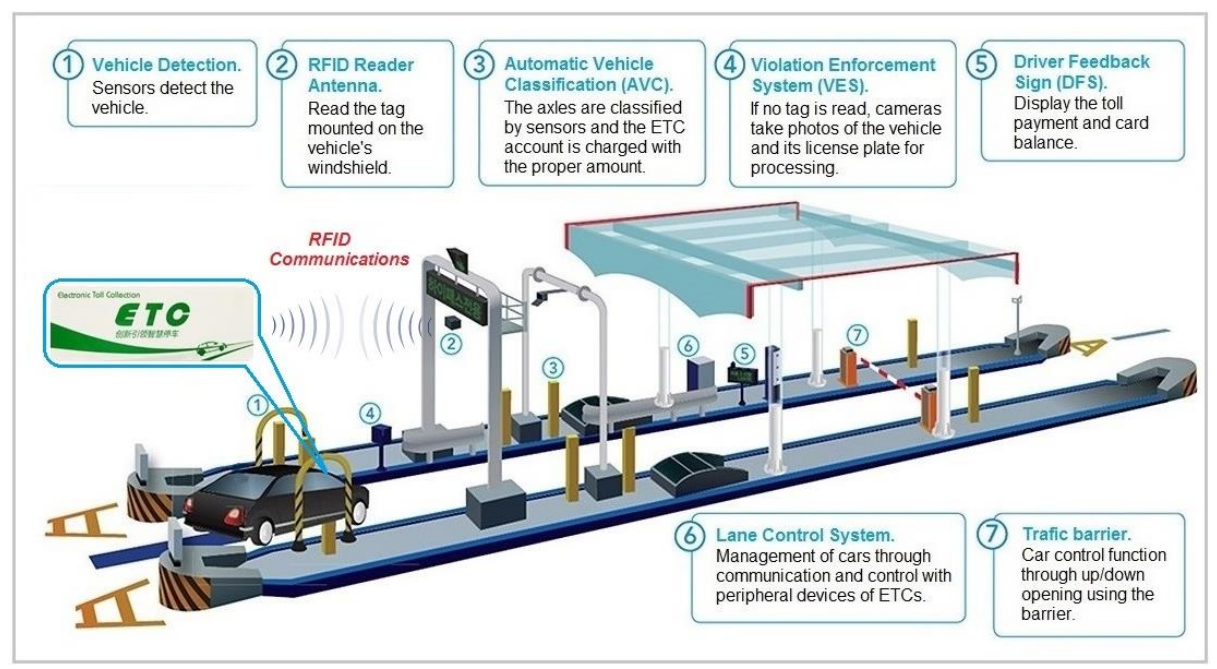

Fig. 3. Toll Booth.

There exist other solutions that can be utilized in Electronic Toll Collection, and these are the use of RFID headlight tags and license plate RFID tags. The inconvenience of the headlight tag is that it is attached at the exterior of the headlight, so its life time is shorter since is exposed to the outdoors environment, humidity, mud, etc. In addition, the disadvantage of the license plate RFID tags is that its cost is higher, since it requires a plastic housing. For these reasons, it has become more popular to use RFID windshield tags, since it is attached in the interior of the vehicle. 


\section{$2 \quad$ Antenna Design and Electromagnetic Simulations}

Figure 4 shows the proposed windshield tag antenna and it was drawn and modeled in Momentum from Advanced Design System. The dimensions of the tag antenna are 70 $\mathrm{mm}$ x $20 \mathrm{~mm}$. The chip used was Alien Higgs 3 with an impedance in its port of 18.58 - j165.94 ohms for the frequency of 866.6 MHz. So, in order to obtain a good impedance matching between antenna and the chip, the antenna must be designed such that, it presents in its port the conjugate complex impedance of the chip, and in this case is $18.58+\mathrm{j} 165.94 \mathrm{ohms}$. The antenna tracks were modeled with a conductivity of $5,000,000 \mathrm{Siemens} / \mathrm{m}$, with a thickness of $0.004 \mathrm{~mm}$. The antenna inlay was printed on PET with a thickness of $0.0508 \mathrm{~mm}$ and with a relative dielectric constant of 3.2. Also, the tag is modeled on a surface of a glass, with thickness of $4.4 \mathrm{~mm}$ and with a relative dielectric constant of 5.0.

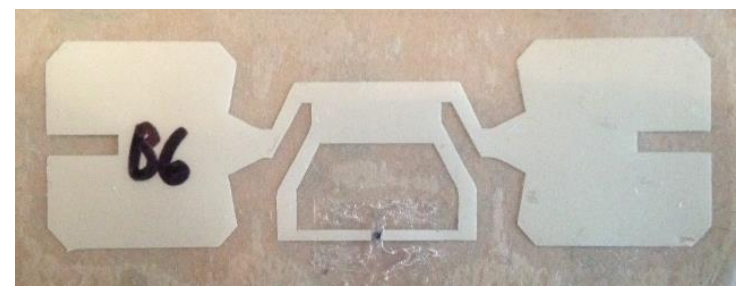

Fig. 4. Proposed windshield tag.

Figure 5 shows the simulated impedance matching and return loss of the proposed windshield tag antenna. It can be observed that the antenna was presenting in its ports a very good impedance matching of $19.052+\mathrm{j} 165.705$ at $866.6 \mathrm{MHz}$ with a return loss of $-37 \mathrm{~dB}$.

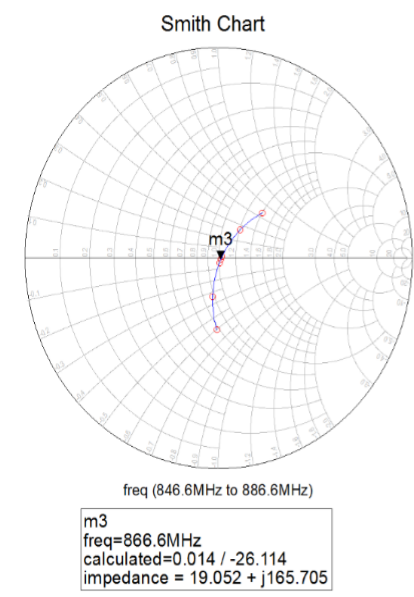

(a)

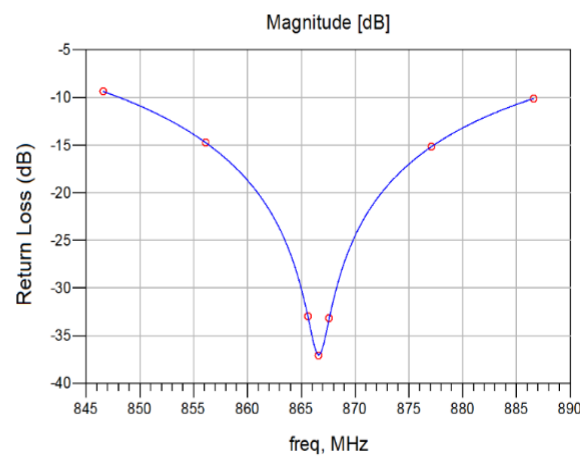

(b)

Fig. 5. Impedance Matching (a) Smith Chart and (b) Return Loss. 


\section{$3 \quad$ Prototyping and Characterization}

As it can be noticed, the tag was only modeled for glass and the real application where it was desired to make it operate properly is on vehicle windshields. After the electromagnetic analysis, the tag was prototyped and tested on different locations of the windshield.

Table 1. Testing conditions and equipment.

\begin{tabular}{ll}
\hline \multicolumn{1}{c}{ Characteristic } & \multicolumn{1}{c}{ Specification } \\
\hline Reader & Sirit INfinity 610 UHF RFID \\
Frequency & $866.6 \mathrm{MHz}$ \\
ERP & $2 \mathrm{Watts}$ \\
& Mti - MT-242020/NV; Gain: 9.5 dBi; Linear; \\
Reader Antenna & $865-870 \mathrm{MHz}$ \\
& $56 "$ (floor to the mid center of antenna). \\
Reader Antenna Height, angle and & Perpendicular to the Pavement. \\
localization & Reader Antenna in front of vehicle. \\
Vehicle & Acura TL 2016 \\
\hline
\end{tabular}

The optimization basically consists in adding or removing segments of conductor on critical sections of the prototype. So, the CAD drawing have to be updated, reprototyped, tested and validated until the read range is increased. The criteria for windshield tag optimization were focusing in improve the performance given by the worst location, and this, indirectly, improved the performance given by the rest of locations. So, this way the design fulfilled a commitment of performance between the different critical and important locations on the windshield. On the other hand, in order to optimize the radiation pattern, this process can be repeated for different angles and heights of the reader antenna with respect to the front of the vehicle. Once discovered that the tag cannot achieve even larger reading ranges, the optimization is over.

Figure 6 illustrates the important locations of a windshield where the tag may be installed and table 2 shows the corresponding performances obtained from characterizing the sensitivity of the tag and with this, it was calculated the experimental read range.

The experimental read range RRE [m] was determined as follows [22]:

$$
E I R P=P_{T_{X}} \mathrm{G}_{\mathrm{TX}},
$$

where EIRP is Equivalent Isotropic Radiated Power (note that the maximum allowed value for Euro Asiatic RFID standard is $3.28 \mathrm{~W}), \mathrm{P}_{\mathrm{Tx}}[\mathrm{dBm}]$ is the transmit power, $\mathrm{G}_{\mathrm{Tx}}$ $[\mathrm{dB}]$ is the reader antenna gain:

$$
R R_{E}=d \sqrt{\frac{E I R P}{P_{\min } G_{T g} L_{c}}},
$$

where $\mathrm{d}[\mathrm{m}]$ is the distance between reader antenna and tag antenna, and Lc $=-2 \mathrm{~dB}$ is measured cable losses. The RFID reader provides an output power from $5 \mathrm{dBm}$ to 32 $\mathrm{dBm}$ at the operating frequency of $865-868 \mathrm{MHz}$. A query command can be sent to the 
tag (mounted face to face to the reader antenna), which replies with its identification code. The minimum transmit power required to activate the tag is Pmin and $\mathrm{G}_{\mathrm{Tg}}[\mathrm{dB}]$ is the tag antenna gain.

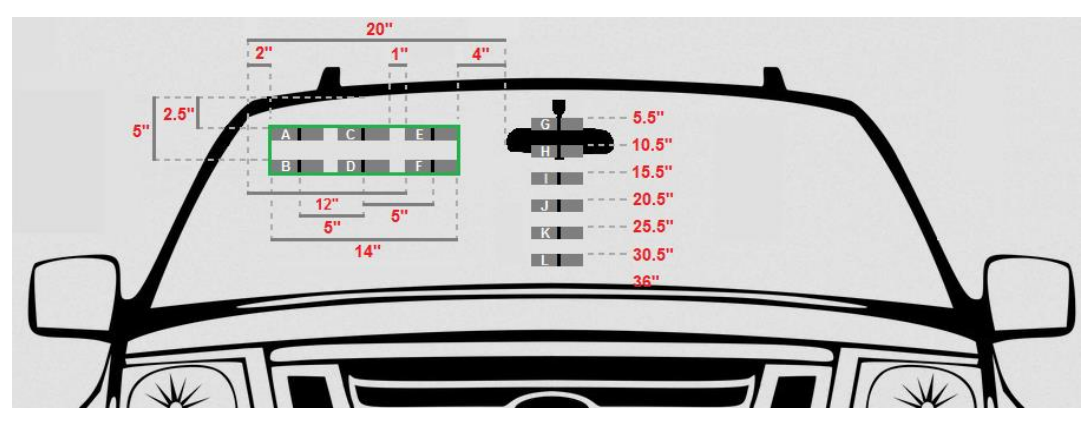

Fig. 6. Locations of the tag on the windshield.

Table 2. Experimental read ranges (meters) of the proposed windshield tag vs Smartrac Dogbone on the different locations of the windshield. (*Med means Median and *Ave means Average).

\begin{tabular}{cccccccc}
\hline $\begin{array}{c}\text { Tag Location } \\
\text { IDesign }\end{array}$ & $\mathrm{A}$ & $\mathrm{B}$ & $\mathrm{C}$ & $\mathrm{D}$ & $\mathrm{E}$ & $\mathrm{F}$ & $\mathrm{G}$ \\
\hline $\begin{array}{c}\text { Proposed } \\
\text { Smartrac }\end{array}$ & 16.8 & 13 & 15.6 & 11.5 & 16.6 & 16 & 16.6 \\
\hline Dogbone & 14.4 & 11.2 & 11.3 & 9.1 & 12.7 & 12.6 & 12.7 \\
\hline $\begin{array}{c}\text { Tag Location } \\
\text { IDesign }\end{array}$ & $\mathrm{H}$ & $\mathrm{I}$ & $\mathrm{J}$ & $\mathrm{K}$ & $\mathrm{L}$ & $\mathrm{Med}$ \\
\hline $\begin{array}{c}\text { Proposed } \\
\text { Smartrac }\end{array}$ & 8.7 & 11.7 & 12.1 & 4.7 & 7.9 & 12.6 \\
Dogbone & 7.5 & 9 & 9.2 & 4.3 & 6.7 & 10.2 \\
\hline
\end{tabular}

* The performance of the tag may slightly vary due:

I. Different Windshield Thicknesses and Protective Films on Different Vehicles.

II. Shape of the vehicle.

III. Doors and Windows Opened or Closed.

IV. The Car is Manned or Not.

V. If Manned, Different Body Mass of the Person and Proximity to the Tag.

VI. Position, Angle and Height of the Reader Antenna with Respect the Vehicle.

VII. Position, Angle and Height of the Tag with Respect the Antenna.

VIII. Etc. 


\section{Discussion and Conclusion}

Evidently, the performance given by the proposed design surpassed the performance given by the tag Smartrac Dogbone. It is a mistake to tune a windshield tag only for glass, due to the existence of metal surfaces around of the windshield that considerably affect the tag antenna performance and these needs to be considered on the design. It was found that the best location to install the tags is close to the top corners of the windshield and the worst is in the center of the windshield.

\section{References}

1. Finkenzeller, K.: RFID Handbook: Radio-Frequency Identification Fundamentals and Applications". 2nd ed., Hoboken, NJ: Wiley (2004)

2. Nikitin, P. V.; Rao, K.V.S.: Theory and measurement of backscattering from RFID tags. IEEE Antennas and Propagation Magazine, 2006, vol. 48, no 6, pp. 212-218.

3. Rao, K.V.S., Nikitin, P.V., Lam, S. F.: Antenna design for UHF RFID tags: A review and a practical application. IEEE Transactions on antennas and propagation, vol. 53, no 12, p. 3870-3876 (2005)

4. Marrocco, G.: The art of UHF RFID antenna design: Impedance-matching and sizereduction techniques. IEEE antennas and propagation magazine, vol. 50, no. 1 (2008)

5. Loo, Chye-Hwa, et al.: Chip impedance matching for UHF RFID tag antenna design. Progress in Electromagnetics Research, vol. 81, pp. 359-370 (2008)

6. Chen, Sung-Lin, Lin, Ken-Huang: Characterization of RFID strap using single-ended probe. IEEE Transactions on Instrumentation and Measurement, vol. 58, no 10, pp. 3619-3626 (2009)

7. Mabrouk, M., et al.: A Broadband UHF TAG Antenna for Near-Field and Far-Field RFID Communications. Laboratoire GRESCOM, SUPCOM de Tunis, University de Carthage, Radioengineering, vol. 23, no. 4 (2014)

8. Mun, Byeonggwi, et al.: A compact dual-band RFID tag antenna mountable on metallic objects. International Journal of Antennas and Propagation, vol. 2015 (2015)

9. Turcu, C., (ed.): Radio Frequency Identification Fundamentals and Applications: Design Methods and Solutions. [Online] Sciyo.com (2010)

10. Ranasinghe, D. Ch., et al.: Small UHF RFID label antenna design and limitations. In: IEEE International Workshop on Antenna technology: Small Antennas and Novel Metamaterials (2006)

11. Cho, Chihyun, Park, Ikmo, Choo, Hosung: Design of a circularly polarized tag antenna for increased reading range. IEEE Transactions on Antennas and Propagation, vol. 57, no. 10, pp. 3418-3422 (2009)

12. Chen, Hong-Dean, et al.: Compact Circularly Polarized Meandered-Loop Antenna for UHFBand RFID Tag. IEEE Antennas and Wireless Propagation Letters, vol. 15, pp. 1602-1605 (2016)

13. Lee, J.-W., Lee, B.: Design of high-Q UHF radio-frequency identification tag antennas for an increased read range. IET microwaves, antennas \& propagation, vol. 2, no. 7, pp. 711717 (2008)

14. Chen, Hong-Dean, et al.: Circularly polarized loop tag antenna for long reading range RFID applications. IEEE Antennas and Wireless Propagation Letters, vol. 12, pp. 1460-1463 (2013)

15. Zhang, Jun, Long, Yunliang: A novel metal-mountable electrically small antenna for RFID tag applications with practical guidelines for the antenna design. IEEE Transactions on Antennas and Propagation, vol. 62, no. 11, pp. 5820-5829 (2014) 
16. Nikitin, P.V., et al.: Power reflection coefficient analysis for complex impedances in RFID tag design. IEEE Transactions on Microwave Theory and Techniques, vol. 53, no. 9, pp. 2721-2725 (2005)

17. Andrenko, A. S.: Conformal fractal loop antennas for RFID tag applications. In: Applied Electromagnetics and Communications, ICECom 2005, IEEE 18th International Conference on, pp. 1-6 (2005)

18. Santiago, A. G., Costa, J. R.; Fernandes, C. A.: Broadband UHF RFID passive tag antenna for near-body applications. IEEE Antennas and Wireless Propagation Letters, vol. 12, pp. 136-139 (2013)

19. Zamora, G., et al.: Design and synthesis methodology for UHF-RFID tags based on the Tmatch network. IEEE Transactions on Microwave Theory and Techniques, vol. 61, no. 12, pp. 4090-4098 (2013)

20. Li, Chonghua: Automatic vehicle identification (AVI) system based on RFID. In: AntiCounterfeiting Security and Identification in Communication (ASID), IEEE International Conference on, pp. 281-284 (2010)

21. Kalantri, R., Parekar, A., Mohite, A., Kankapurkar, R.: RFID based toll collection system. International Journal of Computer Science and Information Technologies 5, no. 2: 2582-5 (2014)

22. Liu, Hsien-Wen, Yang, Chang-Fa, Ku, Chia-Hao: Novel miniature monopole tag antenna for UHF RFID applications. IEEE Antennas and Wireless Propagation Letters 9: 363-366 (2010) 